\title{
EFECTO DE LA DIGESTIÓN EN LA BIODISPONIBILIDAD DE PÉPTIDOS CON ACTIVIDAD BIOLÓGICA
}

\section{EFFECT OF DIGESTION ON BIOAVALABILITY OF PEPTIDES WITH BIOLOGICAL ACTIVITY}

\author{
Maira Segura-Campos, Luis Chel-Guerrero, David Betancur-Ancona \\ Facultad de Ingeniería Química, Campus de Ingenierías y Ciencias Exactas, \\ Universidad Autónoma de Yucatán. Yucatán, México.
}

\begin{abstract}
The potential beneficial effect of the biopeptides depends on its capacity to reach intact the organs where they will carry out their function. However, once in the organism the peptides should cross a series of potential barriers that they should avoid in order to not be inactivated. The digestive enzymes, the absorption through the gastrointestinal tract and the sanguine proteases can produce the hydrolysis of them and to generate inactive fragments or with a higher activity that its sequence precursor. Therefore, it is difficult to establish a direct relationship among the biological activity in vitro and in vivo, due mainly to the peptides bioavailability after oral administration. This should be taken into account at the moment to transfer the results from the investigation to the food industry for the elaboration and commercialization of nutraceutical products.
\end{abstract}

Key words: Peptides, biological activity, digestion, absorption, bioavailability.

Este trabajo fue recibido el 6 de Mayo de 2010 y aceptado para ser publicado el 2 de Julio de 2010.

\section{INTRODUCCIÓN}

Hoy en día, diversas investigaciones están dirigidas al estudio de las proteínas y sus productos, es decir al rompimiento de los enlaces peptídicos generando péptidos de menor tamaño. Dicha ruptura puede producirse mediante métodos fermentativos, utilizando bacterias ácido lácticas; métodos químicos, es decir, por tratamiento con ácidos o bases; o mediante métodos biológicos utilizando enzimas; siendo la hidrólisis ácida y la enzimática las dos principales formas de obtenerlos (1). Algunos péptidos obtenidos de diferentes fuentes alimenticias han mostrado efectos marcadamente positivos a la salud al funcionar como antihipertensivos, antioxidantes, anticancerígenos, antimicrobianos o anticariogénicos, por mencionar algunos ejemplos. Por esa razón, se conocen como péptidos biológicamente activos o péptidos funcionales, debido a que las secuencias de aminoácidos que estaban inactivas en el seno de su proteína de origen, presentan propiedades especiales una vez que se liberan por acción de las enzimas (2).

Los péptidos bioactivos son componentes importantes de los denominados alimentos funcionales, los cuales hoy en día son foco de estudio, tanto por su evidente valor terapéutico como por su gran relevancia para la industria alimentaria, dada la gran repercusión económica que supone la comercialización de este tipo de alimentos y de los productos que los contienen (3).

El interés por el estudio de dichos péptidos se ha enfatizado debido a la importancia que tiene el consumo de alimentos en la salud debido a que estudios epidemiológicos han demostrado que existe una buena relación entre la dieta de las personas y la incidencia de enfermedades crónico degenerativas (4). Sin embargo, la elevada inestabilidad de los péptidos en el entorno biológico, la rápida eliminación del plasma, pobre transportabilidad a través de las membranas y fácil metabolismo en el tracto gastrointestinal a limitado su uso terapéutico.

Los experimentos in vivo, y los ensayos clínicos son necesarios para demostrar los efectos fisiológicos de los péptidos, siendo los estudios in vitro una alternativa temprana para evaluar la funcionalidad de los mismos por estar basados en mecanismos biológicos. Sin embargo, es difícil establecer una relación directa entre la actividad biológica in vitro y el efecto in vivo, jugando 
un papel importante la biodisponibilidad de los péptidos después de su administración oral.

\section{IMPORTANCIA DE LA DIGESTIÓN Y ABSORCIÓN SOBRE LA BIOACTIVIDAD}

La digestión es la barrera potencial para que los péptidos tengan una aplicación real al alcanzar los tejidos donde han de ejercer su acción en concentraciones suficientes para tener un efecto biológico. Durante el proceso natural de digestión, las enzimas proteolíticas gastrointestinales pueden inactivar péptidos o liberarlos del seno de su proteína de origen donde se encontraban inactivos, presentando propiedades especiales una vez liberados (5). Por lo tanto, para que los péptidos sean utilizados como nutracéuticos y ejerzan un efecto fisiológico in vivo después de su administración oral, es de crucial importancia que permanezcan activos durante la digestión y absorción gastrointestinal para que puedan alcanzar el sistema cardiovascular. Los principales factores que afectan la absorción oral de los péptidos son las diferencias metabólicas, anatómicas, fisiológicas y bioquímicas del tracto gastrointestinal, la actividad enzimática del mismo, la pobre permeabilidad de los biopéptidos al cruzar las membranas biológicas así como su naturaleza hidrofílica y tamaño molecular (6).

No obstante, algunos fragmentos son parcialmente resistentes a los procesos de hidrólisis y son susceptibles de ser absorbidos en cantidades fisiológicamente activas y alcanzar intactos la circulación sanguínea (7).

Lo anterior, solo es posible si el péptido atraviesa las barreras potenciales de la activación o inactivación que pudieran hacerle perder su acción biológica (8) (figura 1).

\section{DIGESTIÓN GASTROINTESTINAL}

La digestión de las proteínas se inicia en el estómago por acción de las pepsinas en particular la A y la C, sin embargo además de la proteólisis en el estómago, la alta acidez del mismohidroliza las proteínas antes de que estas alcancen el intestino para su absorción (9). En el lumen intestinal, las endopeptidasas pancreáticas, principalmente la tripsina, elastasa y quimiotripsinajunto con exopeptidasas como la carboxipeptidasa A y B, producen péptidos de dos a seis residuos aminoacídicos así como aminoácidos libres, los cuales son absorbidos como tales atravesando el ribete estriado de los enterocitoscon ayuda de transportadores o acarreadores (10).

Los oligopéptidos producidos por acción de las enzimas gástricas y pancreáticas son después hidrolizados

\section{FIGURA 1}

Barreras potenciales de activación o inactivación de las proteínas durante la digestión y absorción gastrointestinal

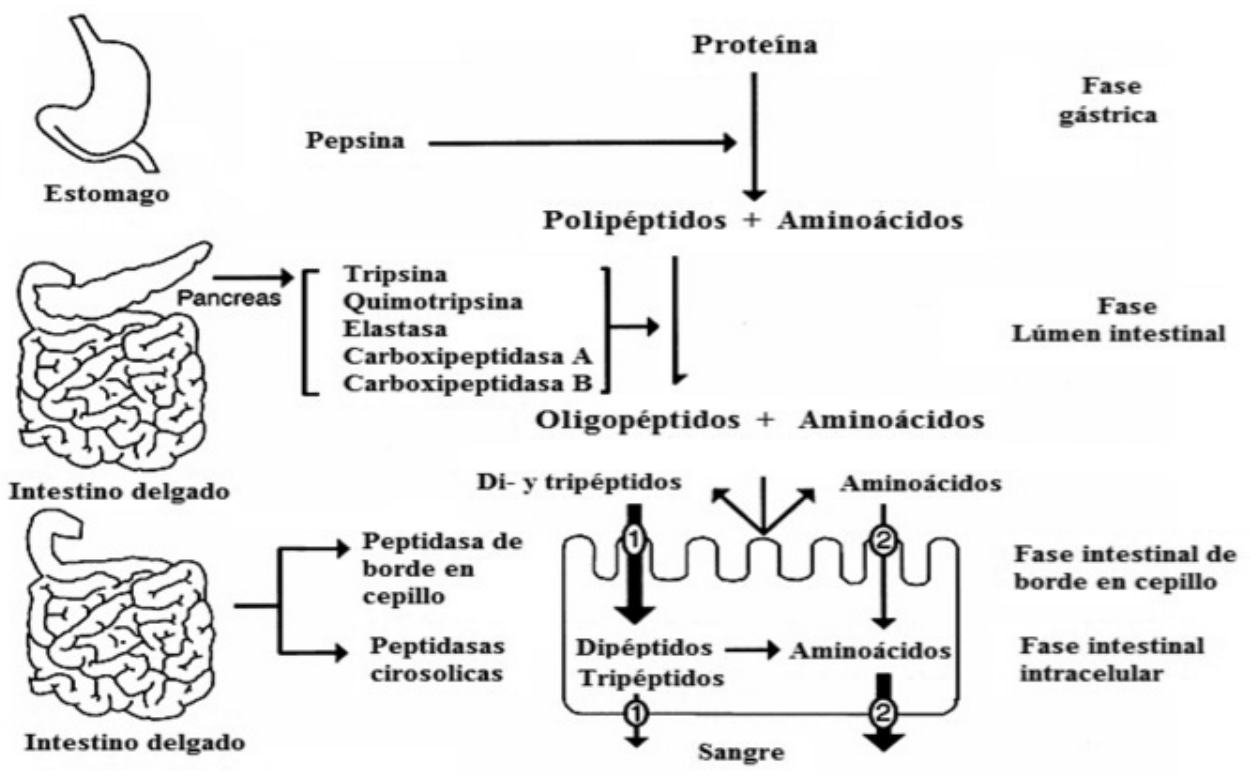


por exo y endopeptidasas en la membrana intestinal de borde en cepillo generando dipéptidos y tripéptidos (9). Posteriormente, los péptidos no digeridos y/o no absorbidos en el intestino delgado entran al intestino grueso o colón a través de la válvula ileocecal donde son metabolizados por la microbiota intestinal,especialmente bacilos del colon como la Escherichiacoli (10). No obstante la barrera gastrointestinal, existe evidencia sustancial en la literatura que sugiere la absorción de proteínas nutricionales y farmacéuticas después de ser administrados por vía oral con la retención de suficiente actividad biológica para su uso terapéutico (9).

\section{ESTABILIDAD Y ACTIVIDAD DE LOS BIOPÉPTIDOS DURANTE LA DIGESTIÓN GASTROINTESTINAL}

La biodisponibilidad de los péptidos depende de la actividad enzimática de las diferentes áreas del tracto gastrointestinal. La primera barrera de los péptidos es el lumen del intestino delgado, el cual contiene gran cantidad de proteasas secretadas por el páncreas y proteasas de las células de la mucosa. La segunda barrera enzimática son las proteasas de la membrana del borde en cepillo de las células epiteliales, las cuales contienen al menos quince peptidasas que en conjunto tienen una amplia especificidad pudiendo degradar tanto proteínas como péptidos (6). Woodley (11), establece que tras su administración oral, una proteína o péptido terapéutico debe resistir la acción de al menos 40 diferentes enzimas durante su paso por el intestino delgado. Además, las peptidasas lisosomales cuyo número se estima en más de 60, también representan una barrera para los péptidos y proteínas que son transportados por las células epiteliales vía endocitosis.

La simulación in vitro de la digestión fisiológica con proteasas gastrointestinales es una herramienta muy útil para evaluar la estabilidad de los biopéptidos frente a las enzimas digestivas (12). De esta manera se emula en dos etapas el proceso de digestión que tiene lugar en el organismo, efectuando en primer lugar una hidrólisis con pepsina a pH ácido y a continuación una digestión con extracto pancreático a pH básico (13). La resistencia de algunos péptidos a las barreras enzimáticas depende en parte de su composición aminoacídica. De esta manera, péptidos con residuos de prolina e hidroxiprolina aislados de la caseína y la gelatina han resistido la degradación de las enzimas digestivas (14). Sin embargo, estudios in vitro de muestran no solo una reducción del potencial biológico por efecto de la hidrólisis sino también un incremento del mismo por efecto de la digestión. Este es el caso del heptapéptidoKVLPVPQ el cual después de la acción de la enzima pancreática carboxipeptidasa A, presentó un incremento significativo del poder de inhibición de la enzima convertidora de angiotensina I (ECA-I) al eliminar el residuo terminal Q; mientras que el hexapéptidoYKVPQL derivado de la as1-caseína perdió su poder antihipertensivo después de ser sometido a la degradación pancreática (15). Por lo tanto, la simulación de la digestión gastrointestinal es una alternativa viable para evaluar no solo la biodisponibilidad de los péptidos sino también la forma activa y el mecanismo de acción de los mismos (16).

\section{ABSORCIÓN INTESTINAL}

Los péptidos que han resistido el proceso de digestión y llegan intactos al intestino, bien pueden ejercer una función local como relajantes de la mucosa gástrica o inhibidores de la secreción de enzimas, o si su acción es sistémica deben atravesar elepitelio y pasar al torrente circulatorio (10). Sin embargo, las diferencias metabólicas y las variaciones anatómicas, fisiológicas y bioquímicas que se presentan en las diferentes partes del tracto gastrointestinal repercuten en la absorción de los mismos. Entre los factores fisiológicos, las diferencias en la composición y grosor de la mucosa, el pH, el área superficial, la actividad enzimática, la bilis, el jugo pancreático y el volumen y contenido de fluido, pueden modificar las relaciones de disolución, solubilidad, tiempos de tránsito, metabolismo y transporte de membrana de los péptidos (6).

La pobre permeabilidad de los péptidos y proteínas terapéuticas a través de las membranas biológicas puede atribuirse a su estructura hidrofílica y tamaño molecular (17). El proceso de permeación puede ser mediado a través de transportadores peptídicos específicos. Dichos transportadores, no solo permiten la absorción de dipéptidos y tripéptidos de manera intacta a través de la membrana intestinal, sino que facilitan la salida de los mismos desde los enterocitos hasta el torrente circundante y evitan que una vez dentro de los mismos sean hidrolizados hasta aminoácidos por acción de diversas peptidasas intracelulares (18).

En este sentido, el transportador PepT1 emplea un gradiente electroquímico transmembrana de protones como fuerza de transporte, el cual se mantiene por el intercambiador $\mathrm{Na}^{+} / \mathrm{H}^{+}$el cual a su vez obtiene energía de la $\mathrm{Na}^{+} / \mathrm{K}^{+}$-ATPasa (19). Además del sistema por transportadores, los péptidos pueden absorberse de manera intacta atravesando la mucosa intestinal mediante diversos mecanismos y ejercer sus efectos biológicos a nivel de tejidos. La ruta para celular se efectúa a través de los espacios intercelulares mediante difusión pasiva, lo cual implica el movimiento de péptidos de bajo peso molecular a favor de un gradiente de concentración, sin 
consumo de energía ni sistema de transporte o portador específico $(20,18)$. En la ruta transcelular, los péptidos ingresan al enterocito a través del borde en cepillo de la membrana apical y se desplazan por el interior del mismo hasta la membrana basolateral por difusión facilitada, es decir mediante el movimiento de los péptidos a través de la membrana a favor de un gradiente de concentración y mediante la presencia de un transportador específico (21).

La presencia en la membrana basolateral del enterocito de diversas proteínas con actividad ATPasa transportadoras de iones específicos, hacen posible la absorción de los péptidos mediante transporte activo, es decir en contra de un gradiente eléctrico o químico, dependiente de la energía liberada del metabolismo celular y de dicho transportador (22). Los péptidos pueden incluso entrar hasta los enterocitosvía endocitosis en donde se observa un enlazamiento a la membrana y la absorción del material en presencia o ausencia de receptores (23) (figura 2).

Con la finalidad de comprender de los mecanismos de absorción intestinal de las biopéptidosque permitan establecer estrategias para maximizar su asimilación y potencial terapéutico,se emplean las células Caco-2, una línea de células procedentes de un carcinoma de colon rectal humano que presentan actividades enzimáticas y mecanismos de transporte similares a los del epitelio del intestino delgado (24). De esta manera Satake y cols. (18) demostraron que la ruta paracelular era el principal mecanismo de transporte del péptido antihipertensivo VPP aunque una pequeña cantidad del mismo se absorvía transcelularmente vía el transportador PepT1.
ESTABILIDAD EN SANGRE

El elevado número de péptidasas que se encuentran en la sangre hace que el tiempo de estabilidad de los péptidos en el plasma sea muy corto, del orden de un minuto (25). Sin embargo, existen evidencias de que ciertas fracciones peptídicas pueden absorberse en el tracto digestivo y ser transportadas por el torrente circulatorio sin ser hidrolizadas (26). Así, Foltz y col. (27) detectaron en el plasma de un grupo de 6 hombre y 6 mujeres los tripéptidos LPP, VPP e IPP con actividad inhibitoria de la ECA-Ial evaluar la biodisponibilidad de un yogurt 10 horas después de su ingesta. De la misma manera, Matsuiy col. (28) detectaron en el plasma de sujetos normotensos el péptido VY derivado de la sardina con actividad inhibidora de la ECA y antihipertensiva después de su absorción trans epitelial dependiente de la dosis.

\section{ESTRATEGIAS PARA MEJORAR LA BIODISPONIBILIDAD DE LOS PÉPTIDOS}

La baja biodisponibilidad de los péptidos debido a las barreras potenciales de la digestión gastrointestinal, pobre transportabilidad a través de las membranas y rápida eliminación del plasma,halimitado elusode los mismos como agentes terapéuticos. Por lo tanto, para efectuar formulaciones de péptidos biodisponibles, se debe inhibir o modular la actividad proteolítica que degrada al péptido; reforzar su transporte paracelular o transcelular; mejorar su penetración a través de la barrera mucosa; incrementar su vida media en la circulación, en los casos en los que se requiera la presencia sostenida

\section{FIGURA 2}

Rutas de transporte de péptidos a través del epitelio intestinal. Transportador de oligopéptidos (T). Transportador P-glicoproteína (P-gp).

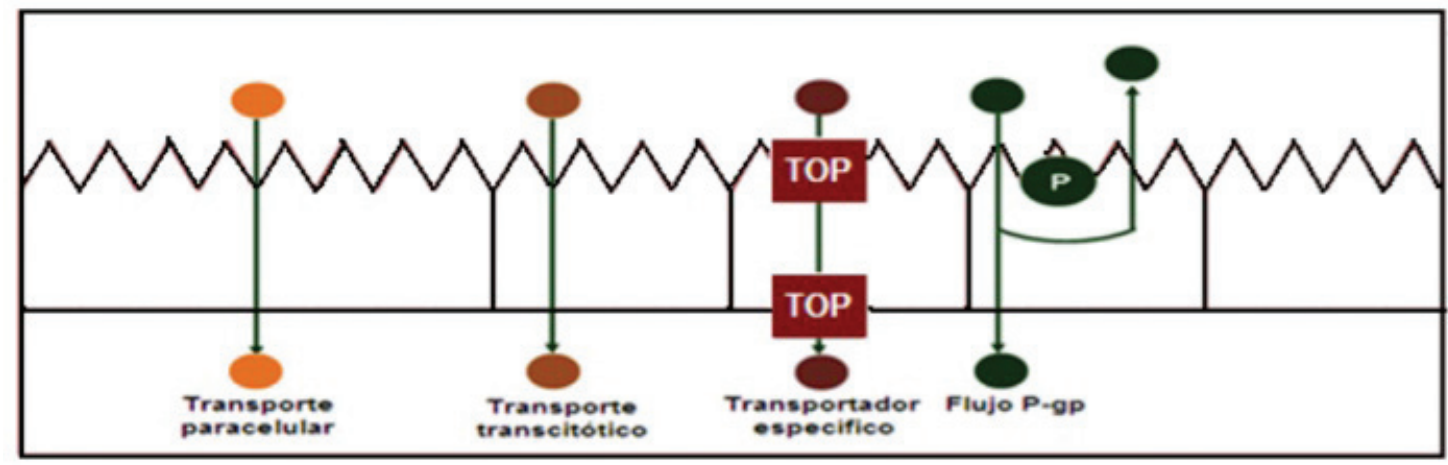


de los mismos para su eficacia terapéutica; desarrollar péptidos análogos resistentes a proteasas que mantengan su actividad biológica, así como estabilizar a los mismos por conjugación a moléculas acarreadoras o por encapsulación (29).

Dentro de las estrategias generadas para mejorar la resistencia de los péptidos a las barreras potenciales de la digestión y absorción gastrointestinal se incluyen, la adición de elementos estructurales no peptídicos que pueden copiar o antagonizar las acciones biológicas de los péptidos naturales (péptido miméticos), modificaciones estructurales como la adición de moléculas de polietilenglicol (pegilación), de ácidos grasos, isoprenoides y colesterol (lipidación) así como de carbohidratos (glicosilación), o modificaciones químicas como la formación de enlaces disulfuro entre residuos de cisteína (ciclización), la sustitución aminoacídica y la N-metilación(30). La reducción del ataque enzimático obtenido con estas modificaciones le permite a los péptidos alcanzar intactos la circulación sanguínea para conferirles entre otras ventajas mayor tiempo de disponibilidad así como aumento de potencia y/o actividad catalítica (la cual también depende de la molécula en cuestión) necesarias para su óptimo funcionamiento (31).

\section{CONCLUSIONES}

El efecto biológico de los péptidos depende de su biodisponibilidad, la cual está determinada por su resistencia a la digestión gastrointestinal. Sin embargo, aún queda mucho camino para poder hacer conclusiones definitivas en este campo, en particular por la necesidad e importancia del estudio del comportamiento de estos compuestos bioactivos en el ser humano. Por lo tanto, para asegurar el efecto biológico de los péptidos, es importante realizar estudios in vitro e in vivo que confirmen su estabilidad, capacidad de absorción y mecanismo de acción que incrementen y diversifiquen las aplicaciones nutracéuticas y farmacéuticas de los mismos. Si pueden demostrarse los efectos beneficiosos en humanos de los distintos tipos de actividad biológica que en principio parecen tener todos estos péptidos, la puerta está abierta para el desarrollo de nuevos productos que unan nutrición y salud, transfiriendo los resultados de la investigación a la industria alimentaria.

\section{RESUMEN}

El potencial efecto beneficioso de los biopéptidos depende de su capacidad para alcanzar intactos los órganos donde van a realizar su función. Sin embargo, una vez en el organismo dichos péptidos deben atravesar una serie de barreras potenciales que pueden inactivarlos.
Las enzimas digestivas, la absorción a través del tracto gastrointestinal y las proteasas sanguíneas pueden producir la hidrólisis de los mismos y generar fragmentos inactivos o con una actividad mayor que su secuencia precursora. Por lo tanto, es difícil establecer una relación directa entre la actividad biológica in vitro e in vivo debido principalmente a la biodisponibilidad de los péptidos después de la administración oral. Esto debe ser tomado en cuenta en el momento de transferir los resultados de la investigación a la industria de alimentos para la elaboración y comercialización de productos nutracéuticos.

Palabras clave: Péptidos, actividad biológica, digestión, absorción, biodisponibilidad.

Dirigir la correspondencia a:

Dr. David Betancur-Ancona

Facultad de Ingeniería Química

Campus de Ingenierías y Ciencias Exactas

Universidad Autónoma de Yucatán, Yucatán,

México.

Periférico Nte. Km. 33.5

Tablaje catastral 13615

Col. Chuburná de Hidalgo Inn

Mérida, Yucatán, México, CP. 97203

Teléfonos: 946-09-56, 946-09-81 y 946-09-89

Fax.(999) 946-09-94

E-mail: bancona@uady.mx

\section{BIBLIOGRAFÍA}

1. Manninen A. Protein hydrolysates in sports and exercise: A brief review. J Sports Sci Med. 2004; 3:60-3.

2. Korhonen H. y Pihlanto, A. Bioactive peptides: Production and functionality. Int Dairy J: 2006; 16: 945-60.

3. Burdock G.A. Carabin I.G. Griffiths J.C. European regulations on nutraceuticals, dietary supplements and functional foods: a framework based on safety. Toxicology 2006; 221(1): 17-27.

4. Dávila A.M. Sangronis E. y Granito M. Leguminosas germinadas o fermentadas: alimentos o ingredientes de alimentos funcionales. Arch Latinoam Nutr. 2003; 53: 348-4.

5. Vermeirssen V. Van Camp J. and Verstraete W. Bioavailability of angiotensin I converting enzyme inhibitory peptides, Br J Nutr. 2004; 92: 357- 66.

6. Lee H.J. Protein drug oral delivery: The recent progress. Arch Pharm Res. 2002; 25 (5): 572-84.

7. Robert P.R. y Zaloga G.P. Dietary bioactive peptides. New horizons 1994; 2: 237-43.

8. Yamamoto N. Maeno M. and Takano T. Purification and characterization of an antihypertensive peptide 
from a yogurt like product fermented by Lactobacillus helveticus CPN4, J Dairy Sci 1999; 82: 1388-93.

9. Soltero R. y Ekwuribe N. The oral delivery of protein and peptide drugs. In: Drug delivery, principles and applications (2005) pp. 106-110.

10. Arhewoh I.M. Ahonkhai E.I. y Okhamafe A.O.Optimising oral systems for the delivery of therapeutic proteins and peptides, African J Biotec. 2005; 4(13): 1591-97.

11. Woodley J.F. Peptidase enzymes of G.I. tract; barriers to peptide delivery, but potential for controlled release. Proc Int Symp. Control Rel Bioact Mater. 1992; 19: 2-5.

12. Matsui T. Yukiyoshi A. Doi S. Sugimoto H. Yamada H. y Matsumoto K. Gastrointestinal enzyme production of bioactive peptides from royal jelly protein and their antihypertensive ability in SHR. J Nutr Biochem. 2002; 13: 80-6.

13. Roufik S. Gauthier S. F. y Turgeon S.L. In vitro digestibility of bioactive peptides derived from bovine beta-lactoglobulin. Int Dairy J 2006; 16: 294-302.

14. Fitzgerald R.J. y Meisel H. Milk protein-derived peptide inhibitors of angiotensin-I- converting enzyme. Br J Nutr. 2000; 84: S33-S7.

15. Maeno M. Yamamoto N. y Takano T. Identification of an antihypertensive peptide from casein hydrolysate produced by a proteinase from Lactobacillus helveticus CP790. J Dairy Sci. 1996; 79: 1316-21.

16. Miguel M. Aleixandre A.M. Ramos M. y LópezFandiño R. Effect of Simulated Gastrointestinal Digestion on the Antihypertensive Properties of ACE-Inhibitory Peptides Derived from Ovalbumin. J Agric Food Chem. 2006; 54: 726-31.

17. Watts L.y Fasano, A. Modulation of intestinal permeability: a novel and innovative approach for the oral delivery of drugs, macromolecules and antigens. Biotechnol Genet Eng Rev 2000;17: 433-53.

18. Satake M. Enjoh M. Nakamura Y. Takano T. Kawamura Y. Arai S. y Shimizu M. Transepithelial transport of the bioactive tripeptide, Val-Pro-Pro, in human intestinal Caco-2 cell monolayers. Bios Biotec Biochem. 2002; 66: 378-84.

19. Brodin B. Uhd Nielsen C. Steffansen B. Frokjaer S. Transport of peptidomimetic drugs by the intestinal Di/tri- peptide transporter, PepT1, Pharm \& Toxicol. 2002; 90: 285-96.
20. Pappenheimer J.R. Dahl C. E. Kanovsky M. L. y Maggio, J.E. Intestinal absorption and excretion of octapeptides composed of D-amino acids, Proc Nat Acad Sci. 1994; 1942-5.

21. Pappenheimer J.R. Michel C.C. Role of villus microcirculation in intestinal absorption of glucose: coupling of epithelial with endothelial transport. J Phys. 2003; 553:561-74.

22. García M.N. Flowers C. Cook J.D. The Caco-2 cell culture system can be used as a model to study food iron availability. J Nutr. 1996; 126:251-58.

23. Ziv E. y Bendayan M. Intestinal absorption of peptides through the enterocytes. Microsc Res Tech. 2000; 49: 346-52.

24. Elimrani I. Lahjouji K. Seidman E. Roy M.J. Mitchell G.A. Qureshi I. Expression and localization of organic cation/carnitine transporter OCTN2 in Caco- 2 cells, American Journal of Physiology. Gastr Liver Phys. 2003; 284(5): G863-71.

25. Matsui T. Imamura M. Oka H. Osajima K. Kimoto K.I. Kawasaki T. y Matsumoto K. Tissue distribution of antihypertensive dipeptide, Val-Tyr, after its single oral administration to spontaneously hypertensive rats, J Peptide Sci. 2004; 10: 535-45.

26. Moskowitz D.W. Is 'somatic' angiotensin-I-converting enzyme a mechanosensor?, Diabetes Technol Therap. 2003; 4: 841-58.

27. Foltz M. Meynen E.E. Bianco V. Van Platerink C. Koning T.M.M.G.Kloek J. Angiotensin Converting Enzyme Inhibitory Peptides from a LactotripeptideEnriched Milk Beverage Are Absorbed Intact into the Circulation J. Nutr 2007; 137: 953-58.

28. Matsui T.Tamaya K. Seki E. Osajima K. Matsumoto K. y Kawasaki T. Absorption of Val-Tyr with in vitro angiotensin I-converting enzyme inhibitory activity into the circulatingblood system of mild hypertensive subjects. Biol Pharma Bull. 2002; 25: 1228-30.

29. Mehta N.M. Oral delivery and recombinant production of peptide hormones. Part I: Making oral delivery possible. Bio Pharm Int 2004;17:38-46.

30. PichereauC. y Allary C. Therapeutic peptides under the spotlight. Eur Biopharm Rev. 2005; 5:1-4.

31. Biron E. Chatterjee J. Ovadia O. Langenegger D. Brueggen J. Improving oral bioavailability of peptides by multiple N-methylation: Somatostatin analogues. Angew Chem 2008; 47: 2595-9. 